PF 2019 (LXXIV): 341-350

\author{
MILENA HEBAL-JEZIERSKA \\ Instytut Slawistyki Zachodniej i Południowej \\ Wydział Polonistyki \\ Uniwersytet Warszawski \\ ul. Krakowskie Przedmieście 26/28 \\ 00-927 Warszawa \\ tel. $(+48) 225520311$ \\ e-mail: m.hebal-jezierska@uw.edu.pl
}

\title{
KOMUNIKACJA INTERKULTUROWA CZESKO-POLSKA - ZARYS PROBLEMATYKI
}

SŁOWA KLUCZOWE: komunikacja interkulturowa czesko-polska.

KEYWORDS: Czech-Polish intercultural communication.

\section{CZECH-POLISH INTERCULTURAL COMMUNICATION - AN INTRODUCTION}

\begin{abstract}
The article considers misunderstandings occurring in intercutural communication between Czechs and Poles, especially in companies employing representatives of these two ethnicities. The first observations and interviews are presented in the context of three selected models: Hall's contextual model, Hofstede's culture dimensions model, and Gasteland's business model. Misunderstandings occurring in intercutural communication between from Czechs and Poles stem from both verbal and non-verbal communication, as well as from differences in mentality and customs.
\end{abstract}

Problematyka komunikacji interkulturowej w związku z licznymi procesami migracyjnymi jest w krajach zachodnich opisywana i badana od wielu lat. Za jej twórcę uznaje się amerykańskiego antropologa, Edwarda T. Halla, a za podstawową publikację przedstawiającą paradygmaty komunikacji interkulturowej ${ }^{1}$ jego książkę Silent Language (Bezgłośny język), wydaną w 1959 r. Komunikacja

\footnotetext{
1 Informacje wstępne zostały opracowane na podstawie artykułu Subocz (2012).
} 
interpersonalna według Halla to przede wszystkim interpersonalne reakcje ludzi, którzy należą do różnych kultur. Popularność oraz praktyczny wymiar tej nauki zaowocował powstaniem kursów z komunikacji interkulturowych w późnych latach 60.

W krajach bloku wschodniego komunikacja interkulturowa dość długo nie wydawała się być potrzebna. Ograniczone możliwości wjazdu do tych krajów oraz wyjazdu z nich nie sprzyjały rozwojowi tej dziedziny nauki. Po zmianie ustroju i otwarciu granic mamy do czynienia z coraz większym umiędzynarodowieniem. Napływ firm i pracowników z innych państw sprawił, że komunikacja i u nas zaczęła się rozwijać. Przedsiębiorstwa i urzędy migracyjne zaczęły dostrzegać także potrzebę szkoleń w tym zakresie. Warto zauważyć, że tematyka ta pozostaje w domenie psychologów, antropologów oraz socjologów, sporadycznie filologów czy kulturoznawców. O ile szkolenia i publikacje interkulturowe o tematyce ogólnej powstają w znacznej mierze dzięki pierwszej grupie wymienionych specjalistów, to w przypadku problematyki ukierunkowanej na konkretny obszar kulturowy (szczególnie niszowy) potrzeba znaleźć osobę zajmującą się żądanym obszarem. O ile wzajemna współpraca między Polakami a pracownikami/imigrantami pochodzącymi $z$ innych kręgów kulturowych wydawała się od razu trudna do realizacji (a więc wymagała znajomości paradygmatów komunikacji interkulturowych, przede wszystkim w jej praktycznym wymiarze), to współpraca między Polakami a Czechami wydawała się przebiegać bez problemów. Był to zatem temat, któremu nie poświęcano przez wiele lat szczególnego miejsca ani w publikacjach naukowych, ani w obszarze szkoleń. Urywki informacji zawierały przewodniki po Czechach/Polsce, artykuły popularnonaukowe, ewentualnie fragmenty poświęcone komunikacji interkulturowej w różnych krajach. Niemniej jednak brakuje kompendium naukowego poświęconego czesko-polskiej komunikacji interkulturowej, nie zaobserwowano także popytu na szkolenia interkulturowe poświęcone komunikacji w biznesie między Czechami a Polakami. Od kilku lat trend ten jest stopniowo przełamywany. Co jakiś czas pracownicy oddziałów HR poszukują specjalistów zajmujących się właśnie tym obszarem komunikacji interkulturowej. W niniejszej publikacji zostaną przedstawione wybrane problemy związane z czesko-polską komunikacją interkulturową. W artykule są prezentowane pierwsze wnioski i hipotezy, które mają zostać poddane głębszej analizie w następnych fazach badania. Wybrane zachowania językowe są przedstawiane w paradygmatach właściwych dla komunikacji interkulturowej oraz zarządzania organizacjami: wysoki i niski kontekst kultury Halla, wymiary kultury Hofstedego, modele biznesowe Gastelanda. 


\section{Specyfika komunikacji interkulturowej}

Przebieg komunikacji rozumianej jako proces przekazywania informacji jest według niektórych modeli (por. rys. 1) obarczony przekształceniami przekazywanego komunikatu, poczynając od tego, co zamierza nadawca powiedzieć, to co naprawdę powiedział, przez to jak wypowiedź zrozumiał odbiorca, kończąc na postaci komunikatu werbalnie parafrazowanego przez odbiorcę.

Rys. 1. Deformacja komunikatu (Mikuláštík 2010).

To, co zamieza Komunikat tak, jak powiedzieć nadawca został zrozumiany przez odbiorcę

To, co naprawdę powiedział nadawca

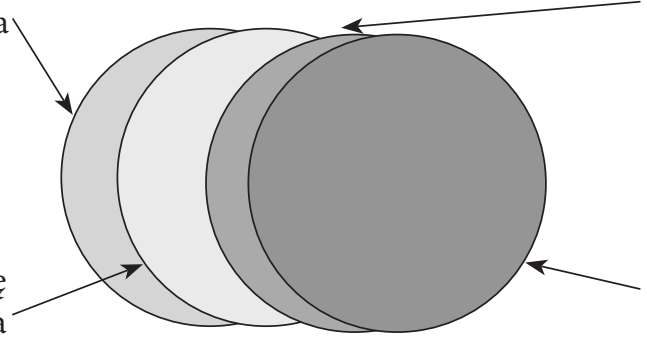

Postać komunikatu sparafrazowanego słowami odbiorcy

$\mathrm{Na}$ odbiór informacji niezgodnej z zamiarem nadawcy może mieć wpływ wiele czynników, wśród nich błędy językowe ${ }^{2}$ tj.:

- stereotypizacja myślenia/myślenie stereotypowe,

- zbyt mała liczba pytań,

- brak upewnienia się, czy się poprawnie zrozumiało komunikat,

- podsuwanie własnych pomysłów,

- niesłuchanie aktywne,

- przebijanie się argumentami,

- niesprawdzanie potrzeb, przyczyn,

- brak obserwacji sygnałów niewerbalnych,

- brak empatii,

- niejasny i skomplikowany sposób wyrażania się.

W komunikacji interkulturowej wyżej wymienione błędy nabierają innego wymiaru. Ponadto dochodzą do tego nieporozumienia związane z błędami właściwymi komunikacji interkulturowej, do której zaliczają się $e^{3}$ (Jaklová 2018):

2 Aleš Kabátek - blog 2016 (usunięty).

3 Błędy te wymienia Jaklová w swoim referacie, powołując się ogólnie na teoretyków komunikacji interkulturowej tj. B. Müller-Jacquier, J. Bolten, K. H. Flechsig. 
- leksyka a socjalne znaczenie pojęć,

- przebieg zachowania podczas mówienia, struktura rozmowy,

- poruszane tematy,

- frazy używane w społeczeństwie, rytualizacja komunikacji,

- bezpośredniość/pośredniość komunikacji

- czynniki parawerbalne (rytm, tempo, melodia, akcent, pauzy itd.),

- czynniki niewerbalne.

Warto tu także wymienić różnice w mentalności, w zwyczajach, stereotypy dotyczące narodowości, przedmiotów, sytuacji. Ponadto użycie w komunikacji trzeciego języka (często jest nim język angielski) nierodzimego dla żadnego z rozmówców nastręcza dodatkowych problemów związanych z nadaniem komunikatu i właściwym go zrozumieniem.

\section{Stereotypizacja myślenia jako podstawowe źródło nieporozumień w komunikacji czesko-polskiej}

Głównym źródłem nieporozumień zachodzących w komunikacji czesko-polskiej, szczególnie na płaszczyźnie biznesowej, jest stereotyp podobieństwa mentalności i kultury obu narodów. Przy planowaniu lub nawiązaniu współpracy przeważa myślenie, że na tle kulturowym nie powinno dochodzić do większych problemów niż w przypadku pracowników tej samej narodowości. Pracodawcy na tym etapie nie myślą o zamawianiu szkolenia lub konsultingu $\mathrm{z}$ interkulturowości. Niemniej jednak różnice w mentalności doprowadzają niejednokrotnie do problemów komunikacyjnych, mogących w niektórych przypadkach opóźnić realizację projektu. Warto zaznaczyć, że częściej do tego typu problemów dochodzi w relacjach podwładny - szef, rzadziej w grupie mieszanej na tym samym poziomie struktury firmy.

\section{Badania naukowe a podobieństwo kulturowe Czechów i Polaków}

Powszechne mniemanie o podobieństwu mentalności i kultur Czech i Polski jest tylko częściowo potwierdzane w modelach pozwalających na ich porównanie, tj.:

- wysoki i niski kontekst kultury według Halla,

- wymiary kultury według Hofstedego,

- modele biznesowe według Gastelanda. 


\subsection{Wysoki i niski kontekst według Halla}

Jednym z paradygmatów komunikacji interkulturowej jest model Edwarda Twitchella Halla. W zależności od roli kontekstu w komunikacji wyróżnia się kultury o niskim lub wysokim kontekście (low-context culture oraz high context culture). W kulturze niskiego kontekstu komunikacja ma charakter bezpośredni, dosłowny. Mniej ważna jest komunikacja niewerbalna, zminimalizowana jest możliwość mówienia/czytania między wierszami. Rolą słów jest przekazywanie znaczenia. W krajach wysokiego kontekstu natomiast mamy do czynienia w komunikacją niebezpośrednią, w której duże znaczenie odgrywa czynniki niewerbalny. Znaczenia nie są przekazywane w sposób dosłowny, ale często są ukryte pomiędzy wierszami (na podst. Štrach 2009). Kraje Europy środkowej i wschodniej są zaliczane do wysokiego kontekstu kultury lub do przejściowego $\mathrm{z}$ tendencją do zachowań bliższych kulturom wysokiego kontekstu, którymi przedstawicielami są: Bliski i Daleki Wschód, kraje śródziemnomorskie, Afryki, Ameryka Łacińska. Kultury niskiego kontekstu są natomiast reprezentowane przez m.in. Ameryka Północna, Skandynawia, Szwajcaria, Niemcy, Australia.

Po pierwszych, jeszcze niereprezentawnych, próbkach badawczych można postawić hipotezę, że komunikacja czeska ma niższy kontekst od polskiej, co mogłoby być wytłumaczeniem niektórych czesko-polskich nieporozumień komunikacyjnych. Wskazują na to wybrane wypowiedzi respondentów czeskich narzekających na brak bezpośredniości, celu w przekazywanych przez Polaków komunikatach, a także nieumiejętności przyznania się przełożonym do niezrozumienia komunikatu, niewiedzy itp. Łączy się to z niezadawaniem pytań, niepodejmowaniem prób upewniania się, czy się poprawnie zrozumiało przekazywany komunikat. Niższy czeski kontest mógłby być także efektem wieloletniego wpływu języka niemieckiego na czeszczyznę.

Opisane tu kwestie muszą jednak zostać poddane dalszej weryfikacji ze względu na brak reprezentatywności próbki.

\subsection{Wymiary kultury według Hofstedego}

Zestawienie modelu wymiarów polskiej i czeskiej kultury pokazuje podobieństwa różnice między nimi. Mogą mieć one wpływ i na komunikację. Obie kultury są zaliczane bardziej do kultur indywidualistycznych niż kolektywistycznych (wartość ok. 60 punktów). Źródłem ${ }^{4}$ identyfikacji jest tu jednostka, a zarządzanie

4 Ogólne charakterystyki wymiarów kultury zostały przejęte z Encyklopedii zarządzania dostępnej na stronie: https://mfiles.pl/pl/index.php/Badanie_Geerta_Hofstede [dostęp 2.12.2019]. 
jest zarządzaniem jednostek. Relacje między pracodawcą i pracownikiem są kontraktem przynoszącym obopólne korzyści. Liczy się zatem bardziej interes jednostki niż interes grupy. Decyzje dotyczące zatrudnienia i awansu wynikają z obowiązujących przepisów i zależą od umiejętności i osiągnięć pracowników.

Rysunek 1 Zestawienie wymiarów kultury Polski i Republiki Czeskiej wg Hofstedego ${ }^{5}$

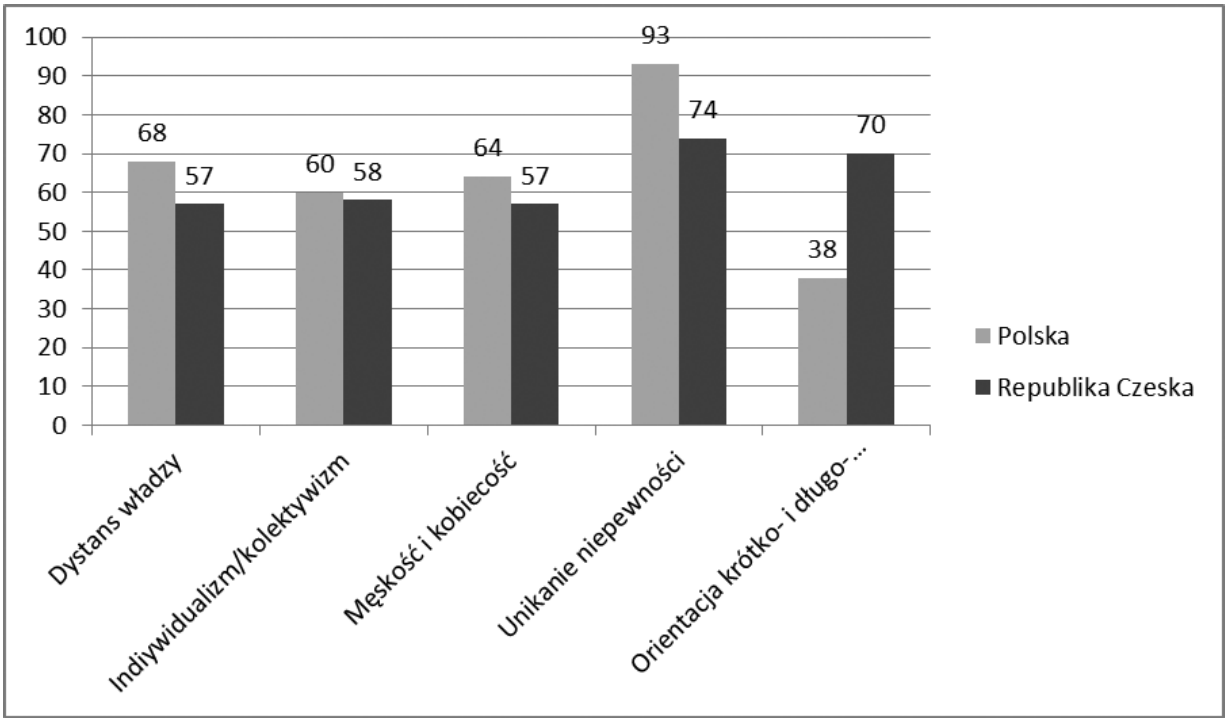

Podobną wartość w obu kulturach ma także wymiar, którego miarą jest rola płci w kulturze. Obie kultury według podanej wartości są bardziej męskie niż żeńskie, z tym że Czechy mają te czynniki bardziej wyrównane (męska kultura ma wartość 57, żeńska - 43). Ta pozornie niewielka punktowa różnica jest jednak dostrzegalna przez respondentów. Czesi stawiają bardziej na współpracę w relacji z przełożonym, co może oznaczać bardziej otwartą komunikację czeskiego szefa $\mathrm{z}$ podwładnymi. W sytuacji pracowników mieszanych na tym tle mogą zachodzić konflikty, a zatem bardziej bezpośrednia, zmniejszająca dystans komunikacja czeska natrafia na niezrozumienie.

Wzajemny szok dla obu stron wywołują także obyczaje związane z przywilejami kobiecymi, np. przepuszczanie kobiety w drzwiach, pomoc przy zdejmowaniu okrycia wierzchniego, np. palta. Zachowania te raczej nieobecne w Czechach wywołują zdziwienie, często niezadowolenie Polek. Reakcję zdziwienia można zaobserwować także u Czeszek. Nieznacznie większą różnicę (11 punktów)

5 Tabela została wygenerowana przy pomocy narzędzia dostępnego na stronie: https://www. hofstede-insights.com/product/compare-countries/ [dostęp 13.10.2018]. 
pomiędzy obiema kulturami widać w wymiarze dystansu władzy. Pierwsze wywiady pokazują jednak, że różnica w tej kwestii jest odczuwalna. Im większa liczba punktów, tym większa zależność podwładnych od władzy. Rzutuje to także na komunikację między nimi. Jest to kolejny przykład, w którym czeski mniejszy dystans w zachowaniu i komunikacji nie jest kompatybilny z dystansem polskim $w$ relacjach.

Największe różnice kulturowe dotyczą natomiast poziomu unikania niepewności oraz długo- i krótkoterminowości. Polska ma znacznie wyższy poziom unikania niepewności (wartość 93) w porównaniu z Czechami (tu wartość wynosi 74\%). Różnice zachodzą, m.in. w poziomie akceptacji dla odmiennych pomysłów (przy silnym unikaniu niepewności dąży się do stłamszenia wszelkich przejawów kreatywności i innowacyjności), liczba przepisów (przy słabym unikaniu niepewności ich liczba jest minimalizowana).

Jeszcze większą różnicę widać w wymiarze długo- i krótkoterminowości. Konflikty związane z zarządzaniem oraz przekazywaniem komunikatu są według pierwszych zebranych danych związane przede wszystkim z planowaniem osiągnięcia wyznaczonego celu (por. tab.1.). Polacy jako przedstawiciele orientacji krótkoterminowej potrzebują odmiennego typu komunikatu niż Czesi.

Tabela 1

\begin{tabular}{|l|l|}
\hline Orientacja krótkoterminowa & Orientacja długoterminowa \\
\hline wysiłek musi przynosić szybkie efekty & $\begin{array}{l}\text { wytrwałość i systematyczne wyniki } \\
\text { w celu stopniowego osiągania rezultatów }\end{array}$ \\
\hline społeczna presja na konsumpcję & $\begin{array}{l}\text { zapobiegliwość, oszczędne } \\
\text { gospodarowanie }\end{array}$ \\
\hline poszanowanie tradycji & poszanowanie okoliczności, \\
\hline dbałość o osobistą stabilizację & dbałość o umiejętność przystosowania się \\
\hline $\begin{array}{l}\text { dbałość o wypełnianie zobowiązań } \\
\text { wynikających z więzi społecznych } \\
\text { i statusu }\end{array}$ & $\begin{array}{l}\text { gotowość do podporządkowania się } \\
\text { osiągnięciu celu }\end{array}$ \\
\hline dbałość o zachowanie twarzy & poczucie wstydu \\
\hline
\end{tabular}

Źródło: Hofstede 2000

\subsection{Modele biznesowe według Gastelanda}

Kolejny model, biznesowy, potwierdza różnice między kulturami na płaszczyźnie biznesowej. Gasteland (2000: 210) wymienia wśród cech charakterystycznych dla polskiej kultury w organizacji: propartnerstwo, ceremonialność, 
polichromiczność, niestałą ekspresyjność. Czechy natomiast są określone jako protransakcyjne, umiarkowanie ceremonialne, monochromiczne, powściągliwe (Gasteland 2000:277). Ze wspólnych cech można zatem wymienić tylko ceremonialność, choć jej poziom nie jest taki sam w obu kulturach. W komunikacji, szczególnie w relacjach międzynarodowych, przejawia się w stosowaniu zwrotów grzecznościowych i tytułów (Olejniczak 2014).

Duże różnice $\mathrm{w}$ stylu komunikowania są związane z cechą propartnerstwa/ protransakcyjności. O tym pisze Olejniczak (2014): w kulturze protransakcyjnej mówi się to, co się myśli i myśli się to, co się mówi. Osoby z kultury propartnerskiej dążą do harmonii i miłych relacji, zatem mówią dookoła, nie używają słowa „nie”, a w zamian powiedzą „to trudne”, „może”, „zastanowię się”. Jest to kolejny przykład potwierdzenia przez teortetyczne modele wypowiedzi respondentów czeskich i polskich, w których czeska strona narzeka na brak bezpośredniej komunikacji, natomiast polska strona nie umie przekazać komunikatu tak, jak tego oczekuje partner czeski. Problem ten, nierozwiązany zawczasu, wpływa negatywnie na realizację zadań, opóźniając go, lub w skrajnych przypadkach uniemożliwiając wykonanie zadania. Jest to też kolejny argument wzmacniający hipotezę o niższym kontekście kultury czeskiej od polskiej warto poddać głębszej analizie.

Wiąże się to także z cechami powściągliwości (zarezerwowanej dla Czech) oraz niestałej ekspresyjności (charakterystycznej dla Polski). Olejniczak (2014) twierdzi, że w kulturze ekspresyjnej mówimy głośniej i wyraźniej, chcąc podkreślić to, co ważne, dla kultury powściągliwej będzie to oznaczać gniew. [...]. Dla kultury ekspresyjnej niezręczna jest cisza podczas spotkania, podczas gdy osoby z kultury powściągliwej często siedzą w ciszy. Przerywanie wypowiedzi jest także zwyczajowym zachowaniem w kulturze ekspresyjnej, natomiast w kulturze powściągliwej uznane będzie za zachowanie nieuprzejme.

Tabela 2 Kultura ekspresyjna i powściągliwa (Olejniczak 2014: 122)

\begin{tabular}{|c|c|}
\hline Kultura ekspresyjna & Kultura powściągliwa \\
\hline 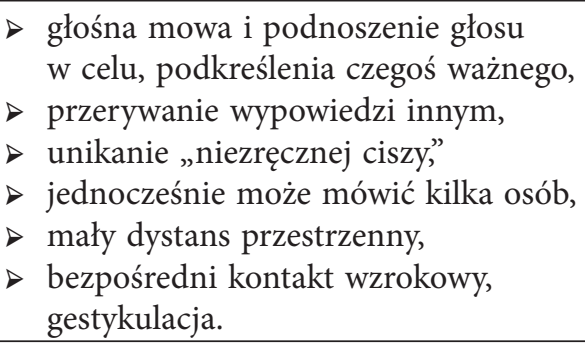 & $\begin{array}{l}>\text { niski ton głosu, } \\
\triangleright \text { dłuższe milczenie w trakcie rozmów, } \\
\triangleright \text { naprzemienne wypowiedzi, } \\
\triangleright \text { duży dystans przestrzenny, } \\
\triangleright \text { unikanie dotyku. }\end{array}$ \\
\hline $\begin{array}{l}\text { Romańskie kraje europejskie, inne } \\
\text { kraje śródziemnomorskie, kraje } \\
\text { latynoamerykańskie }\end{array}$ & $\begin{array}{l}\text { kraje Azji wschodniej i południowo- } \\
\text { wschodniej, nordyckie i inne germańskie } \\
\text { kraje europejskie }\end{array}$ \\
\hline
\end{tabular}


W pierwszych wywiadach zebranych do tego badania respondenci zgłaszali przede wszystkim różnice w kontakcie wzrokowym, zachowaniu dystansu przestrzennego, unikaniu dotyku.

W stosunkach biznesowych problem może stanowić mniejsza ekspresja ciała Czechów w porównaniu z Polakami. Chodzi przede wszystkim o ujawnienie emocji. W sytuacji dotyczącej podwładnych i przełożonych, szef Polak może być postrzegany jako osoba niepanująca nad emocjami, natomiast szef Czech jako człowiek pozbawiony emocji. Dyskomfort dla Czechów stanowi także mniejsza potrzeba dotyku. Dotyczy to raczej sfery prywatnej niż biznesowej. Problemem są pocałunki oraz formy przytulania się przy powitaniu i pożegnaniu. Zdziwienie powoduje także mniejszy dystans przestrzenny Polaków, a w przypadku Polaków większy dystans przestrzenny Czechów.

Do największych różnic pomiędzy Czechami a Polakami należy jednak kontakt wzrokowy. Wbrew opisowi zawartemu w tabelce, z której wynika, że kultura ekspresyjna ma silniejszy kontakt wzrokowy niż kultura powściągliwa, w przypadku czesko-polskim mamy do czynienia z sytuacją odwrotną. Czesi mają bowiem o wiele silniejszy kontakt wzrokowy od Polaków. Na tym tle dochodzi do mylnych interpretacji wzajemnych naturalnych zachowań. $\mathrm{W}$ trakcie rozmowy naturalny kontakt wzrokowy Polaków może być odbierany jako zatajanie prawdy, nieszczerość. Dla Polaków natomiast silny czeski kontakt wzrokowy powoduje dyskomfort, poczucie przesłuchania. W trakcie toastu sprawa wydaje się być jeszcze bardziej poważna. Niepopatrzenie w oczy Czechowi w tym momencie jest poważnym uchybieniem w zakresie etykiety, powoduje zdziwienie, niezrozumienie sytuacji. Podobne skojarzenia mają Polacy, widząc natarczywy ich zdaniem wzrok. W niektórych osobach może to nawet wzbudzić agresję.

Z repertuaru gestów respondenci czescy wymieniali gest ręki dotykającej szyi (propozycja wypicia alkoholu, najczęściej twardego) jako gest dla nich niezrozumiały. Kojarzył im się ze ścięciem. Wyjątek stanowiły osoby, które znają kulturę Słowian Wschodnich.

Nieporozumienia komunikacyjne może także nastręczać zaliczenie Polski do kultur polichromicznych, a Czechy - do kultur monochromicznych. W kulturach monochromicznych przywiązuje się większą wagę niż w polichromicznych do punktualności, nieprzerywania spotkań czy możliwych zmianach w harmonogramie (Olejniczak 2014). W przypadku czesko-polskim największy problem stanowi dotrzymanie harmonogramu, co wymusza zmianę w kontruowaniu komunikatów. Kwestia ta była już poruszona przy omawianiu wymiaru długoi krótkoterminowości.

Reasumując, $\mathrm{z}$ pierwszych badań, przeprowadzonych $\mathrm{w}$ formie obserwacji i wywiadów wśród pracowników firm zatrudniających Czechów i Polaków, ujętych kontekście wybranych trzech modeli: model kontekstowości Halla, model 
wymarów kultury Hofstedego oraz model biznesowy Gastelanda, wynika, że nieporozumienia występujące w komunikacji interkuturowej między Czechami a Polakami mają źródło zarówno w komunikacji werbalnej i niewerbalnej, jak i w odmiennej mentalności i zwyczajach. Kwestie te, jak i postawiona w artykule hipoteza o niższym kontekście kulturowym czeskim od polskiego, zostaną poddane dalszym badaniom i głębszej analizie.

\section{Bibliografia}

Bętkowska Justyna, Skraba Krzysztof, https://mfiles.pl/pl/index.php/Badanie_Geerta_ Hofstede [dostęp 10.12.2018].

Gasteland Richard, 2000, Różnice kulturowe a zachowania w biznesie, Warszawa.

Hall Edward T, 1987, Bezgłośny język. Warszawa.

Hofstede Geert, 2000, Kultury i organizacje, Warszawa.

https://www.hofstede-insights.com/product/compare-countries/ [dostęp 13.10.2018].

Jaklová Alena, Komunikace, interkulutrní migkomm.jcu.cz/doc/prispevky/jaklova_3. doc [dostęp 10.12.2018].

Konecki Krzysztof, Chomczyński Piotr (red.), 2007, Zarządzanie organizacjami. Kulturowe uwarunkowania zarządzania zasobami ludzkimi, Łódź.

Matsumoto David, Juang Linda, 2007, Psychologia międzykulturowa, Gdańsk.

Mikuláštík Milan, 2010, Komunikační dovednosti v praxi, Praha.

Olejniczak Aleksandra, 2014, Wpływ różnic kulturowych na rozwój organizacji, „Studia i Prace Wydziału Nauk Ekonomicznych i Zarządzania” nr 37, t. 3, s. 117-125.

Rosa Grażyna, Ostrowska Izabela, Słupińska Kamila, Gracz Leszek, 2018, Komunikacja międzykulturowa w biznesie, Łódź.

Samovar A. Larry, Porter E. Richard, Stefani A. Lisa, 1998, Communication between cultures, Wadsworth.

Subocz Dawid, 2012, Geert Hofstede - praktyczne zastosowanie wymiarów kultur narodowych, „Annales universitatis Mariae Curie-Skłodowska”, t. XXV, 1-2 sectio j.

Štrach Pavel, 2009, Mezinárodní management, Praha.

Szopski Marek, 2005, Komunikowanie międzykulturowe, Warszawa.

\section{Streszczenie}

Artykuł omawia najważniejsze cechy interkulturowe, które łączą i różnią Polaków i Czechów. Ze wstępnego badania firm zatrudniających obywateli Czech i Polski wynika, że różnice interkulturowe mogą w znacznej mierze utrudnić osiągnięcie celu biznesowego. Artykuł łączy językoznawstwo z modelami stosowanymi w zarządzaniu. 